\title{
Radiofrequency Catheter Ablation of Parahisian Accessory Pathway
}

\author{
Szilamér Korodi', István Kovács', Edvin Benedek², András Mester², Laura Jani², Alexandra \\ Stănescu², Imre Benedek \\ ${ }^{1}$ Clinic of Cardiology, University of Medicine and Pharmacy, Tîrgu Mureș, Romania \\ ${ }^{2}$ Center of Advanced Research in Multimodality Cardiac Imaging, Cardio Med Medical Center, Tîrgu Mureș, Romania
}

\section{CORRESPONDENCE \\ István Kovács \\ 38 Gheorghe Marinescu St \\ 540139 Tîrgu Mureș, Romania \\ Tel: +40 265215551 \\ Email:kov_istvan@yahoo.com}

\section{ARTICLE HISTORY}

Received: 10 April, 2016

Accepted: 15 May, 2016
Szilamér Korodi • 38 Gheorghe Marinescu St, 540139 Tîrgu Mureș, Romania, Tel: +40 265215551 Email: szilamerkorodi@yahoo.com

Edvin Benedek • 76, 22 Decembrie 1989 St, 540124 Tîrgu Mureș, Romania, Tel: +40 265217333 Email: edvinke87@gmail.com

András Mester • 76, 22 Decembrie 1989 St, 540124 Tîrgu Mureș, Romania, Tel: +40 265217333 Email: andras.mester@yahoo.com

Laura Jani • 76, 22 Decembrie 1989 St, 540124 Tîrgu Mureș, Romania, Tel: +40 265217333

Email: jlaura15@yahoo.com

Alexandra Stănescu • 76, 22 Decembrie 1989 St, 540124 Tîrgu Mureș, Romania, Tel: +40 265217333 Email: alexandrastanescu90@gmail.com

Imre Benedek • 38 Gheorghe Marinescu St, 540139 Tîrgu Mureș, Romania, Tel: +40 265215551

Email: imrebenedek@yahoo.com

\begin{abstract}
Radiofrequency catheter ablation of parahisian accessory pathways in pre-excitation syndrome is a challenging task, due to the extremely high risk of complete atrioventricular block. In this brief report we describe the case of a 32 year-old man presenting a parahisian accessory pathway, who has been successfully treated by radiofrequency ablation. Radiofrequency catheter ablation using low-power radiofrequency current is considered to be the most appropiate method of ablation in adult patients.
\end{abstract}

Keywords: pre-excitation, parahisian accessory pathway, ablation, low-power radiofrequency current, right bundle branch block

\section{INTRODUCTION}

Palpitation is a common symptom of Wolf-Parkinson White (WPW) syndrome. The presence of an accessory pathway (AP) contributes to the occurrence of episodes of atrioventricular (AV) re-entrant tachycardias, usually via the orthodromic type of re-entry mechanism..$^{1,2}$ In the general population, the prevalence of accessory pathway is $0.15 \%$ to $0.25 \% .^{3,4}$ In pre-excitation syndromes radiofrequency (RF) catheter ablation is nowadays the routine treatment for AP-facilitated tachycardias. ${ }^{5}$

Accessory pathways may be located close to the His bundle and the AV node, in the anteroseptal, midseptal, and parahisian regions. The ablation of these pathways is associated with a high risk of complete heart block, due to its proximity to the atrioventricular node., ${ }^{2,6-9}$

In this case report, we describe the case of a patient with intermittent preexcitation syndrome, caused by a parahisian accessory pathway.

\section{CASE REPORT}

A 32 year-old man, a professional driver, presented to our hospital with recurrent palpitations with sudden onset and termination, and two unregistered presyn- 


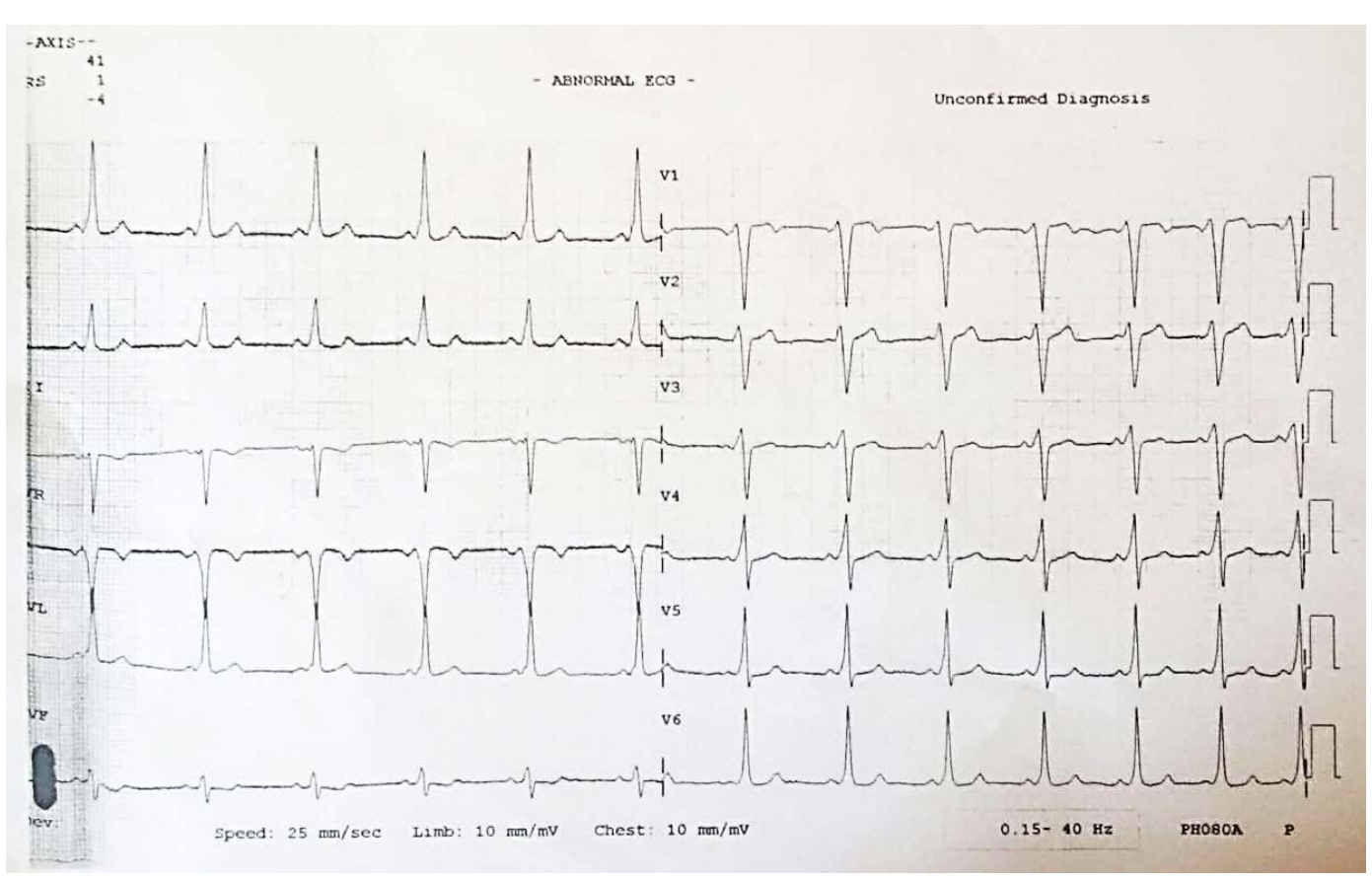

FIGURE 1. 12-lead surface ECG showing sinus rhythm with delta-wave suggesting the existence of a right anteroseptal accessory pathway

copal episodes in the last year. The physical examination findings were normal, blood pressure was $110 / 64 \mathrm{mmHg}$ with pulse rate of 64 beats per minute (bpm). Electrocardiogram (Figure 1) showed sinus rhythm with short PQ interval, suggesting the presence of a right anteroseptal accessory pathway. Echocardiography described a struc- turally normal heart. Laboratory examination revealed normal serum electrolytes values. The informed consent was obtained from the patient for publication of this case report and any accompanying images. The publication of this case was accepted by the Ethics Committee of the Cardio Med Medical Center.

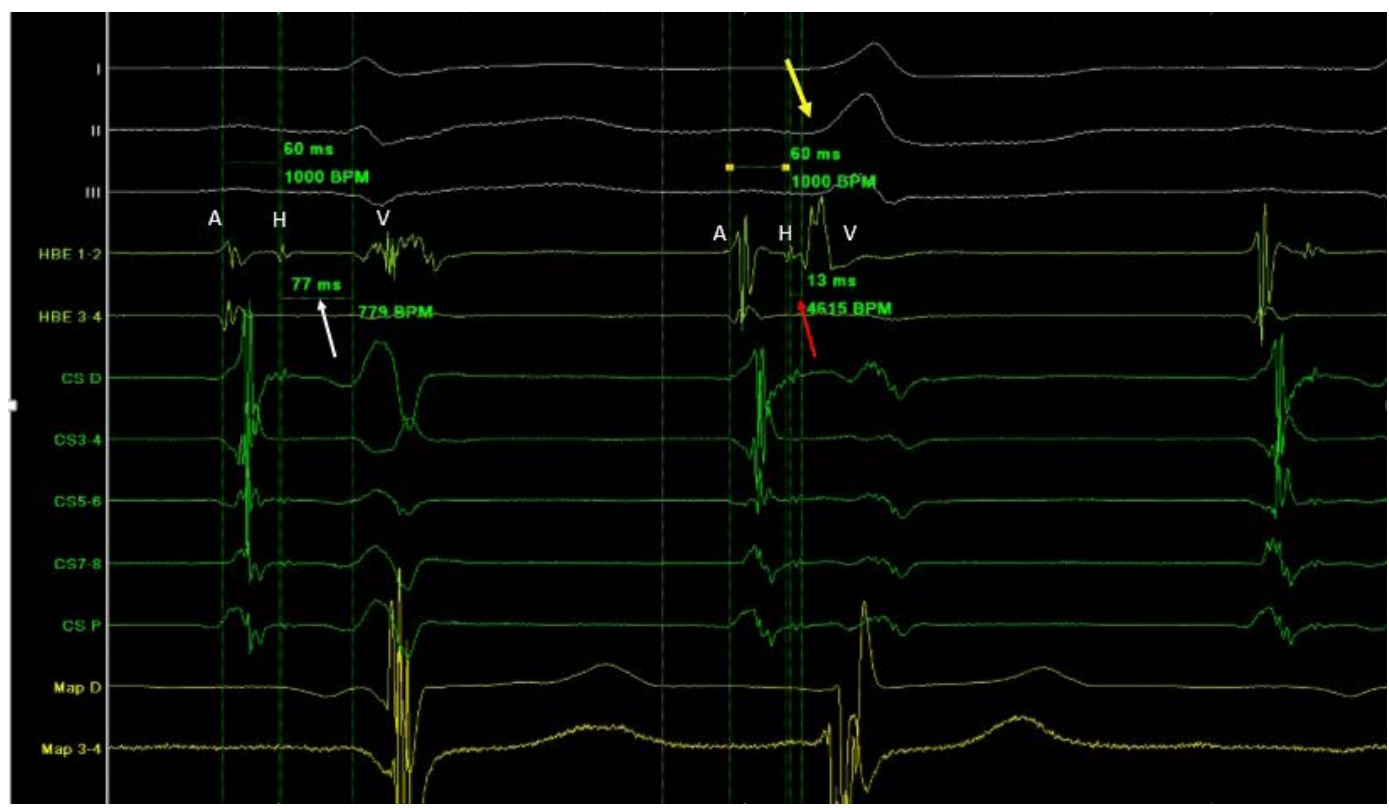

FIGURE 2. Basic electrophysiological recordings during sinus rhythm. Delta wave on DIl lead (yellow arrow). The His electrode (HBE) records intermittent pre-excitations with shortening of H-V interval from 77 msec to 13 msec (white and red arrows). 


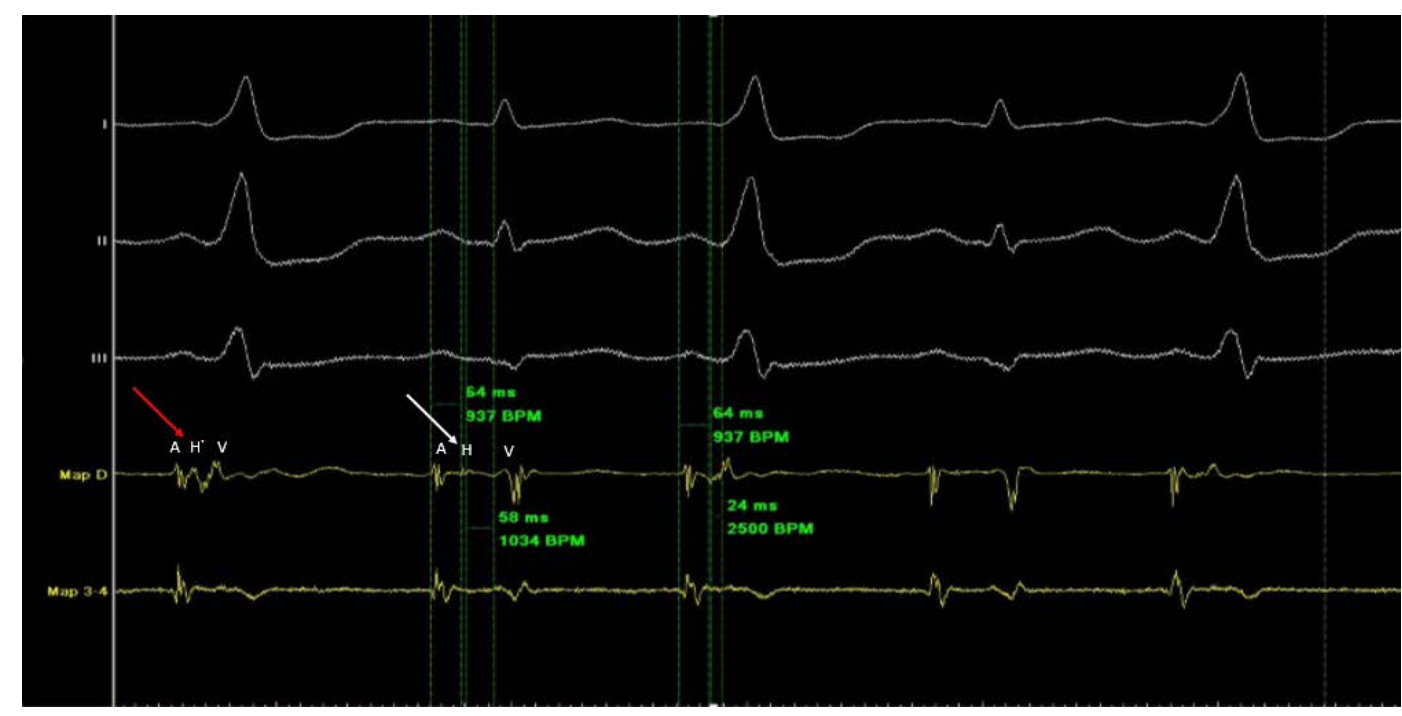

FIGURE 3. Consistent spike of electrical activity in the form of a His-like ( $\left.\mathrm{H}^{\prime}\right)$ wave on ablation catheter, the $\mathrm{H}^{\prime}$ appearing in the same time with the delta-wave on the surface ECG (red arrow). HV interval is 58 msec in normal conduction (white arrow) and H'V interval shortening to $24 \mathrm{msec}$ in pre-excitation.

After obtaining written consent, an electrophysiological study (EPS) was performed. After right femoral vein puncture, we introduced three quadripolar catheters in the high right atrium, His-bundle area and right ventricular apex (ablation catheter), and a steerable decapolar catheter into the coronary sinus.

Basic electrophysiological recordings (Figure 2) showed intermittent pre-excitations on the His catheter with shortening of the $\mathrm{H}-\mathrm{V}$ interval from $77 \mathrm{msec}$ to 13 msec. The presence of His-like wave $\left(\mathrm{H}^{\prime}\right)$ on the ablation catheter (Figure 3), confirmed that the AP was very close to the His-bundle. During the EPS we could not induce reentrant tachycardia, but considering the patient's occupation and his medical history (two presyncopal episodes), after informing the patient on the very high risk for complete AV block during the ablation, which would require the implantation of a permanent pacemaker, the ablation was performed.

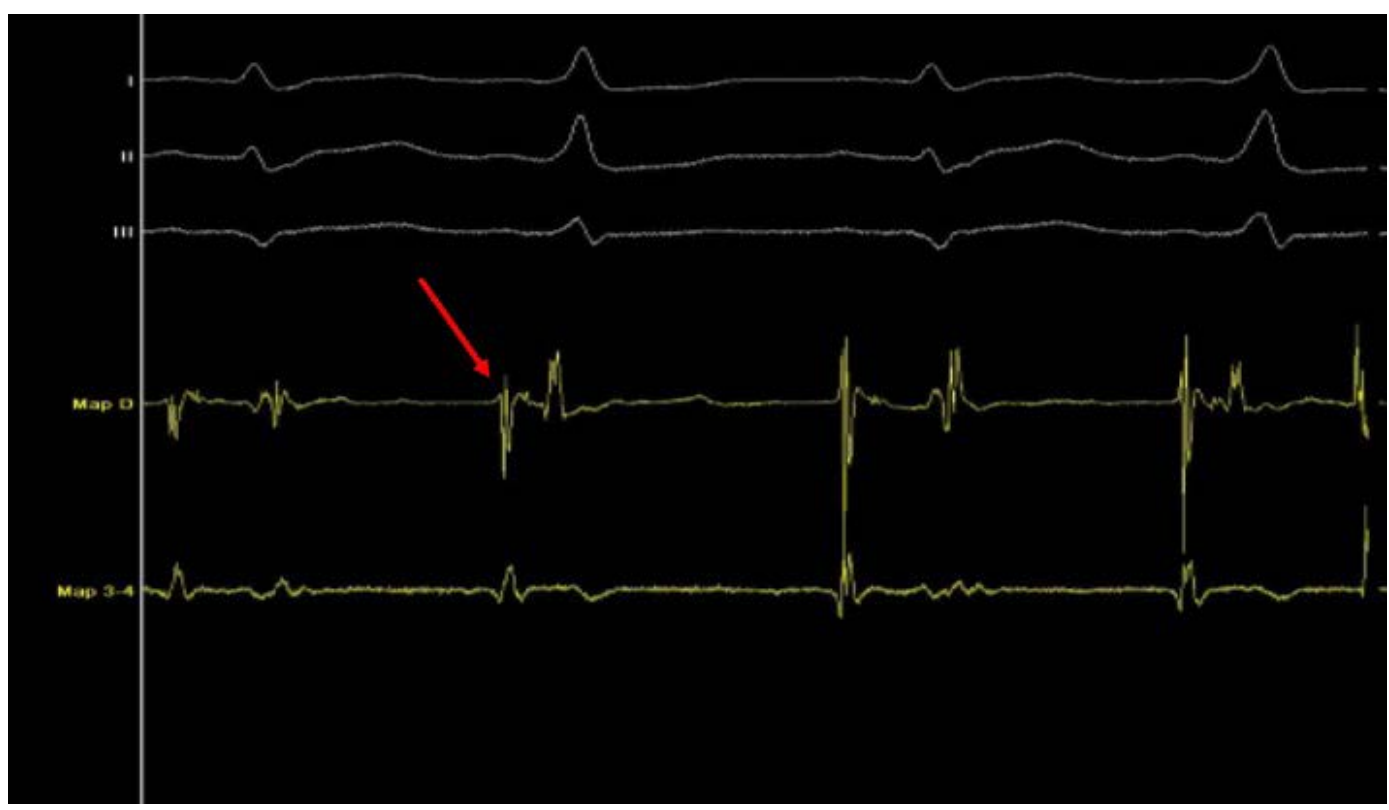

FIGURE 4. The distal tip the ablation catheter is positioned (red arrow) in the inferior area of anteroseptal region, close to the right ventricle. 


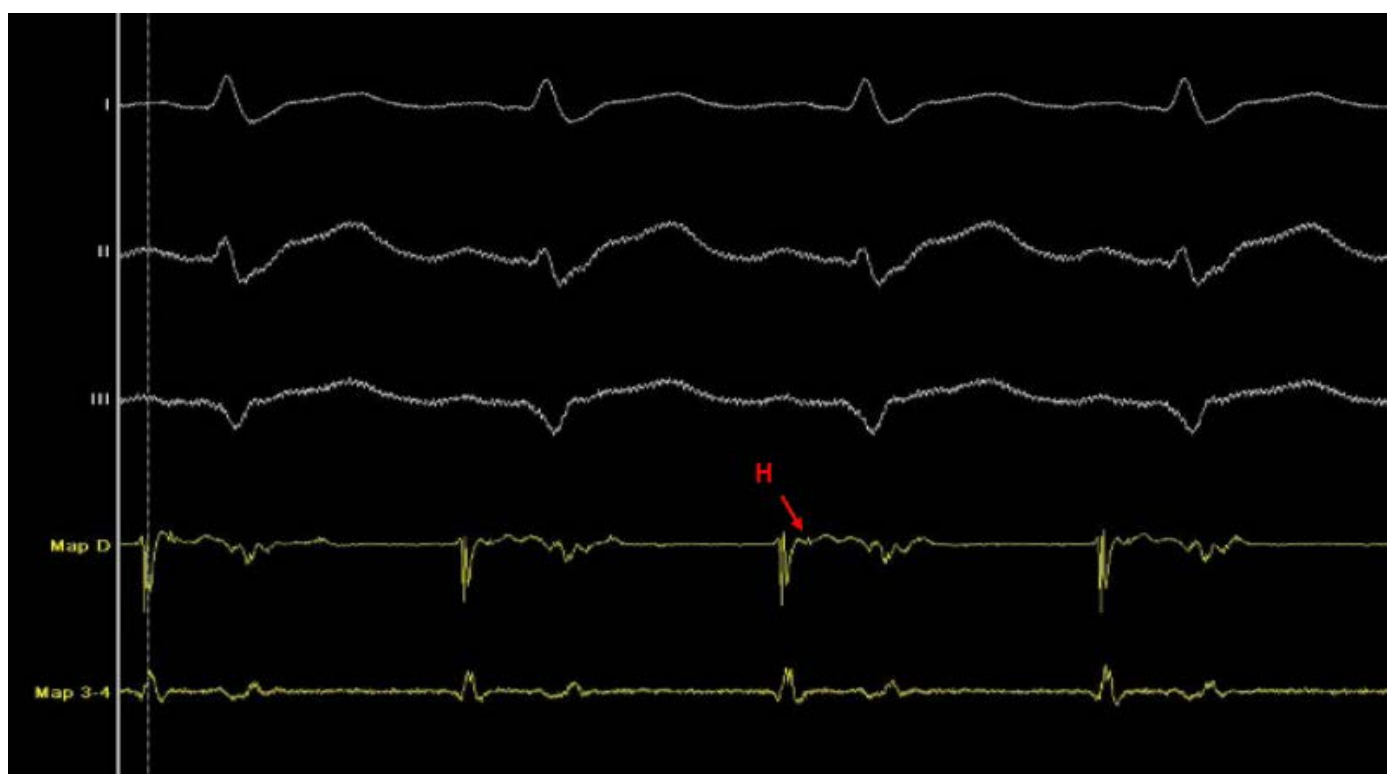

FIGURE 5. Post-ablation ECG with His-sign and right bundle branch block, without AV block

We positioned a $4 \mathrm{~mm}$ deflectable tip ablation catheter (M size, Saint Jude Therapy Ablation) in the right anteroseptal region (Figure 4). The applied radiofrequency current power was progressively increased from $10 \mathrm{~W}$ to 35 $\mathrm{W}$ and the temperature limit was $45^{\circ} \mathrm{C}$. The parahisian AP ablation was successful (Figure 5) after the fourth attempt with a power of $35 \mathrm{~W}$ and temperature of $45^{\circ} \mathrm{C}$, with right bundle branch block on the post-ablation ECG.

The patient was discharged at day 3 post-ablation in a good general state, without recurrence of any symptoms and without any signs of pre-excitation on surface ECG (Figure 6).

At the 1 month follow-up the patient presented without symptoms or any sustained palpitations, 12-lead ECG showed sinus rhythm, RBBB and a normal PR interval.

\section{DISCUSSION}

The ablation of accessory pathways is the recommended treatment in patients who present with episodes of supraventricular tachycardias, but it is also indicated in the case of asymptomatic patients with an ECG pattern of WolffParkinson-White syndrome, when an EPS proves the relatively short anterograde refractory period of the accessory pathway. ${ }^{10}$ Accessory pathway ablation has a $95-99 \%$ success rate with a recurrence of $5-10 \% .{ }^{10-14}$ A severe complication is the complete AV block resulting in the need for permanent pacemaker implantation.

In order to reduce the risk of complications, ablation using lower energy levels can be performed ${ }^{6}$, based on cryothermia-based mapping ${ }^{15}$ or magnetic navigation. ${ }^{16}$

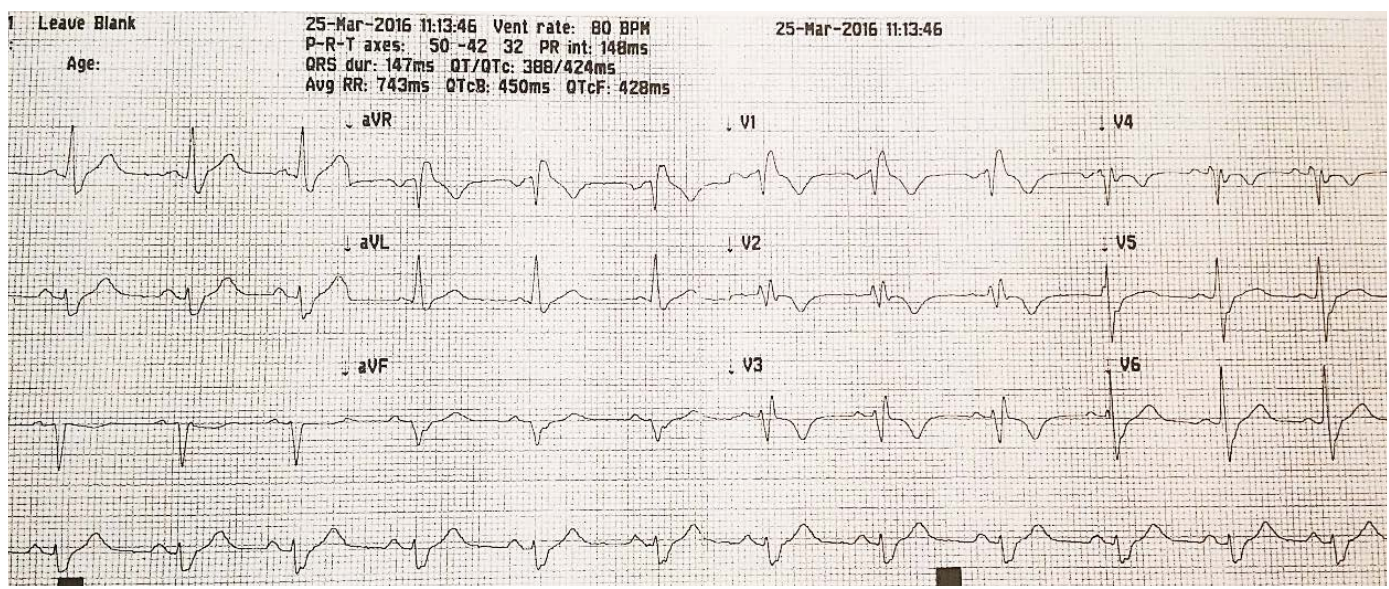

FIGURE 6. 12-lead ECG after the successful ablation, showing sinus rhythm, right bundle branch block, and no pre-excitation. 
The precise classification of the pathways in the above locations using only surface ECG is not possible, despite the existence of dedicated algorithms, since the proposed criteria are not absolutely specific for the sites they refer to. ${ }^{10,17-19}$ Previous reports demonstrate that the risk of causing complete AV block is around $36 \%$ in the case of pathways located close to the normal AV conduction system.6,7,14,20,21 According to the standard classification, these are the anteroseptal and midseptal right accessory pathways, while a specific subgroup includes the parahisian pathways (1.4\%), which are in the vicinity of the AV conduction system. ${ }^{6,7}$

In the case reported here, the temperature of $45^{\circ} \mathrm{C}$ and the $35 \mathrm{~W}$ power of RF current achieved during the fourth $\mathrm{RF}$ application led to a successful ablation of accessory pathways, at the same time avoiding a complete AV block.

\section{CONCLUSION}

Radiofrequency catheter ablation therapy using low-power radiofrequency current should be considered in symptomatic patients with parahisian accessory pathways, at the same time reducing the risk of complete AV block occurrence during the procedure.

\section{CONFLICT OF INTEREST}

None declared.

\section{REFERENCES}

1. Zipes D, Jalife J. Cardiac Electrophysiology: From Cell to Bedside. Saunders, Philadelphia, 2004.

2. Padanilam BJ, Akula D, Vaughn P, Prystowsky EN. Successful Elimination of Concealed Accessory Pathway-Mediated Tachycardia by Ablation of AV Nodal Slow Pathway. J Cardiovasc Electrophysiol. 2006;17:674-677.

3. Begleiter DE, Gernsheimer J, Waseem M. Wolff-ParkinsonWhite syndrome: An uncommon causes of palpitations. Hosp Physician. 2007:43:49-54.

4. Sidhu J, Roberts R. Genetic basis and pathogenesis of familial WPW syndrome. Indian Pacing Electrophysiol J. 2003;3:197-201.

5. Yeh SJ, Wang CC, Wen MS, et al. Characteristics and radiofrequency ablation therapy of intermediate septalaccessory pathway. Am J Cardiol. 1994;73:50-56
6. Haissaguerre M, Marcus F, Poquet F, et al. Electrocardiographic characteristics and catheter ablation of parahissian accessory pathways. Circulation. 1994;90:1124-1128.

7. Gatzoulis K, Apostolopoulos T, Kosteas X, et al. Paraseptal accessory connections in the proximity of the atrioventricular node and the His bundle. Additional observations in relation to the ablation technique in a high risk area. Europace. 2004;6:1-9.

8. Adalet K, Mercanoglu F, Sezer A, Ozer K, Merig M, Erzengin F. Catheter Ablation of Anteroseptal, Midseptal and Para-Hisian Accessory Pathways: How Risky? Turk Kardiyol Dern Ars. 2001;29:105-110

9. Kotsakis AA, Margos PN, Stefanidis AS, Kouvarakos DN, Papasteriadis EG. High Power Radiofrequency Ablation of Incessant Atrioventricular ReEntrant Tachycardia in a Patient with a Para-Hisian Accessory Pathway. Hellenic J Cardiol. 2007;48 (5):306-313.

10. Pappone C, Santinelli V, Rosanio S, et al. Usefulness of invasive electrophysiologic testing to stratify the risk of arrhythmic events in asymptomatic patients with Wolff-Parkinson-White pattern: results from a large prospective long-term follow-up study. J Am Coll Cardiol. 2003;41:239-244

11. Calkins $\mathrm{H}$, Yong P, Miller JM, et al. Catheter ablation of accessory pathways, atrioventricular nodal reentrant tachycardia, and the atrioventricular junction: final results of a prospective, multicenter clinical trial. The Atakr Multicenter Investigators Group. Circulation. 1999;99:262-270.

12. Dagres N, Clague JR, Kottcamp H, et al. Radiofrequency catheter ablation of accessory pathways. Outcome and use of antiarrhythmic drugs during follow-up. Eur Heart J. 1999;20:1826-1832.

13. Kay GN, Epstein AE, Dailey SM, et al. Role of radiofrequency ablation in the management of supraventricular arrhythmias: experience in 760 consecutive patients. J Cardiovasc Electrophysiol. 1993;4:371-389.

14. Calkins H, Prystowsky E, Berger RD, et al. Recurrence of conduction following radiofrequency catheter ablation procedures: relationship to ablation target and electrode temperature. The Atakr Multicenter Investigators Group. J Cardiovasc Electrophysiol. 1996;7:704-712.

15. Lanzotti ME, De Ponti R, Tritto M, Spadacini G, Salerno-Uriarte JA. Successful treatment of anteroseptal accessiory pathways by transvenous cryomapping and cryoablation. Ital Heart J. 2002;3:128-132.

16. Ernst S, Hachiya H, Chun JKR, Ouyang F. Remote catheter ablation of parahisian accessory pathways using a novel magnetic navigation system - A report of two cases. J Cardiovasc Electrophysiol. 2005;16:659-662.

17. Fitzpatrick AP, Gonzales RP, Lesh MD, et al. New algorithm for the localization of accessory atrioventricular connections using a baseline electrocardiogram. J Am Coll Cardiol. 1994;23:107-116.

18. Iturralde P, Araya-Gomez V, Colin L, et al. A new ECG algorithm for the localization of accessory pathways using only the polarity of the QRS complex. J Electrocardiol. 1996;29:289-299.

19. Arruda MS, McClelland JH, Wang $X$, et al. Development and validation of an ECG algorithm for identifying accessory pathway ablation site in WolffParkinson-White syndrome. J Cardiovasc Electrophysiol. 1998;9:2-12.

20. Lin JL, Huang SK, Lai LP, et al. Radiofrequency catheter ablation of septal accessory pathways within the triangle of Koch: importance of energy titration testing other than thelocal electrogram characteristics for identifying the successful target site. Pacing Clin Electrophysiol. 1998:21:1909-1917.

21. Jackman WM, Xunzhang W, Friday $\mathrm{K}$ I, et al. Catheter ablation of accessory atrioventricular pathways (Wolff-Parkinson-White syndrome) by radiofrequency current. N Engl J Med. 1991;324:1605-1611. 